Article

\title{
Logical Analogies: Interpretations, Oppositions, and Probabilism
}

\section{Walter Redmond}

Filosofía, Universidad Popular Autónoma del Estado de Puebla, Puebla 72410, Mexico; wbredmond.wr@gmail.com; Tel.: +1-512-452-5678

Received: 31 December 2018; Accepted: 22 March 2019; Published: 2 April 2019

check for updates

\begin{abstract}
I present two logical systems to show the "analogy of proportionality" common to several interpretations: modality (necessity and possibility), quantification, truth-functional relations, moral attitudes (deontic logic), states of knowledge (epistemic logic), and states of belief (doxastic logic). To display the two underlying analogical relations, I call upon the originally Scholastic convention, recently put to use again, of using squares, hexagons, and octagons "of opposition". A combined epistemic-deontic logic happens to be found in the traditional "probabilist" theory of the "good conscience", and I shall then briefly explain how this is so.
\end{abstract}

Keywords: analogy; modal logic; Scholasticism; square of opposition; hexagon; octagon; probabilism; Aquinas; Leibniz; Hintikka

I present two logical systems that display an "analogy of proportionality" among six areas of interpretation discussed by logicians today and by the Schoolmen of the past: necessity and possibility, quantification, propositional connectives, moral attitudes (deontic logic), and states of knowing and believing (epistemic and doxastic logics). To illustrate the underlying relations, I call upon the convention-Scholastic in origin but recently revived —of using figures "of opposition": squares, hexagons, and octagons. A combined epistemic-deontic logic happens to be found in the traditional "probabilist" debate over the good conscience, and I shall briefly explain how this is so ${ }^{1}$.

\section{The Logical Systems}

The two systems, " $\Sigma 1$ and " $\Sigma 2$ ", can be represented by a hexagon and an octagon, respectively. $\Sigma 2$ contains (logically implies) $\Sigma 1$. Each system has the same two monadic operators, one strong (S) and one weak $(\mathrm{W})$, governing propositional expressions like " $\mathrm{p}$ " or " $\mathrm{q}$ " ("Sp", “Wp"). The operators are interdefinable:

$$
\begin{aligned}
& \mathrm{Sp}={ }_{\mathrm{df}} \sim \mathrm{W} \sim \mathrm{p} \\
& \mathrm{W} p={ }_{\mathrm{df}} \sim S \sim \mathrm{p}
\end{aligned}
$$

The Scholastic "square of opposition" displays the basic logical relations among the propositions (Figure 1, the traditional names are italics):

1 I use the following propositional symbols: $\sim \mathrm{p}$ (negation: "not $\mathrm{p}$ "), $\mathrm{p} \supset \mathrm{q}$ (implication: "if $\mathrm{p}$ then $\mathrm{q}$ "); $\mathrm{p} \wedge \mathrm{q}$ (conjunction: " $\mathrm{p}$ and $\mathrm{q}$ "); $\mathrm{p} \vee \mathrm{q}$ (disjunction: " $\mathrm{p}$ or $\mathrm{q}$ "); $\mathrm{p} \equiv \mathrm{q}$ (equivalence: " $\mathrm{p}$ if and only if $\mathrm{q}$ "); $\mathrm{p} \mid \mathrm{q}$ (non-conjunction: [p $\wedge \mathrm{q}]$ : "not: $\mathrm{p}$ and $\mathrm{q}$ "); $\mathrm{p} \approx \mathrm{q}$ (contradiction or non-equivalence: $\sim[\mathrm{p} \equiv \mathrm{q}]$ : "if $\mathrm{p}$ not $\mathrm{q}$ and if $\mathrm{q}$ not $\mathrm{p}$ "). Quantifiers: $\forall \mathrm{x} \phi \mathrm{x}$ : "for all $\mathrm{x}$, phi- $\mathrm{x}$ " and $\exists \mathrm{x} \phi \mathrm{x}$ : "there is at least one $x$ such that phi- $x$ " (where $\phi x$ is a sentence containing $x$ ). Modal symbols: $\square$ p: "it is necessary that $\mathrm{p}^{\text {" }}$ and $\diamond \mathrm{p}$ : "it is possible that $\mathrm{p}$ ". 


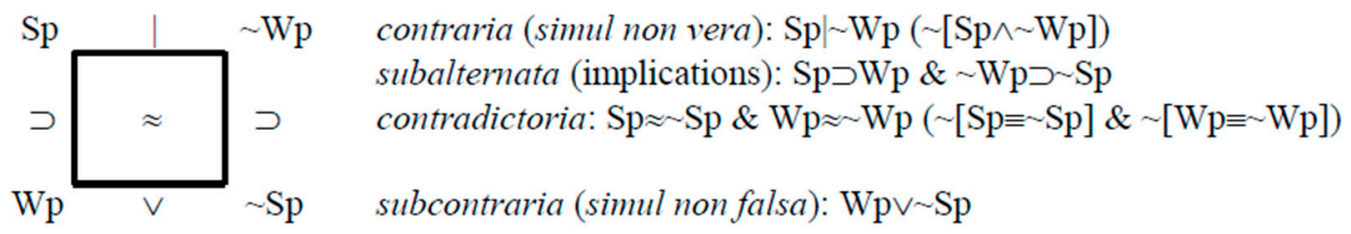

Figure 1. The Scholastic "square of opposition".

Since the operators are interdefined, the square may be expressed with either operator:

$$
\begin{array}{ll}
\text { Sp S p } & \sim W \sim p \sim W p \\
\sim S \sim p \sim S p & W p W \sim p
\end{array}
$$

The first logical system, $\Sigma 1$, is illustrated by a hexagon, which incorporates the square but adds the disjunction of the contraries $S p \vee \sim W p$, and the conjunction of the subcontraries $W p \vee \sim S p$ (Figure 2). The second logical system, $\Sigma 2$, contains the first, but adds implications to and from propositions not governed by the operators $\mathrm{S}$ and W (" $\mathrm{p}$ " and " $\sim \mathrm{p}$ " alone), which constitute, as it were, an "outside link" to the network of propositions affected by the operators:

$$
\begin{array}{ll}
\mathrm{Sp} \supset \mathrm{p} & \sim \mathrm{Wp} \supset \sim \mathrm{p} \\
\mathrm{p} \supset \mathrm{Wp} & \sim \mathrm{p} \supset \sim \mathrm{Sp}
\end{array}
$$

\section{system $\Sigma 1$ (hexagon)}

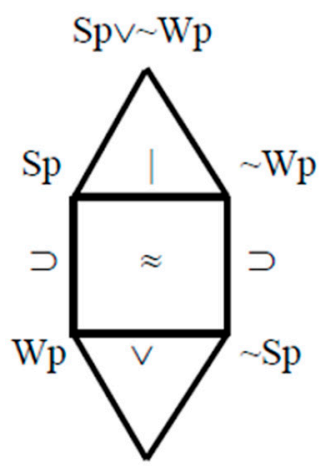

$$
\mathrm{Wp} \wedge \sim \mathrm{Sp}
$$

system $\Sigma 2$ (octagon)

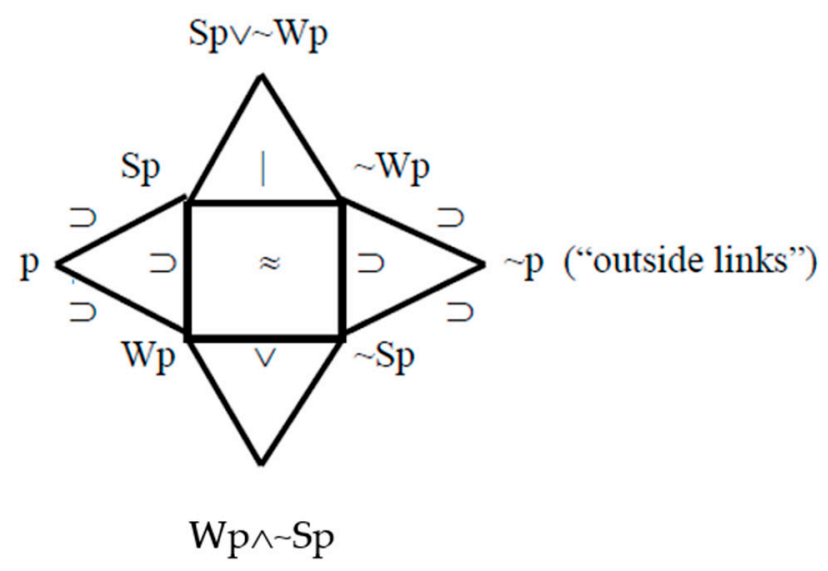

Figure 2. System $\Sigma 1$ and System $\Sigma 2$.

\section{Modality}

A basic interpretation of these systems is (alethic) modality, which includes the notions of necessity, possibility, contingency, actuality, and their negations. Here, the strong operator indicates necessity: $\square \mathrm{p}$ ("it is necessary that $\mathrm{p}^{\prime}$ ) and the weak operator possibility: $\diamond \mathrm{p}$ ("it is possible that $\mathrm{p}$ "). Contingency is the conjunction of the subcontraries: $\diamond \mathrm{p} \wedge \triangleright \sim \mathrm{p}$ ("it is possible that $\mathrm{p}$ and it is possible that not- $\mathrm{p}$ ") or equivalently $\diamond \mathrm{p} \wedge \sim \square \mathrm{p}$ ("p is possible but not necessary"). The disjunction of the contraries, $\square \mathrm{p} \vee \sim \diamond \mathrm{p}$, represents non-contingency ("p is either necessary or impossible"). Also, since necessity implies actuality and actuality implies possibility,

$$
\begin{array}{ll}
\square p \supset p & \square \sim p \supset \sim p \\
p \supset \diamond p & \sim p \supset \triangleright \sim p,
\end{array}
$$

this "outside" link to actuality is expressed in an octagon representing system $\Sigma 2$ (Figure 3): 


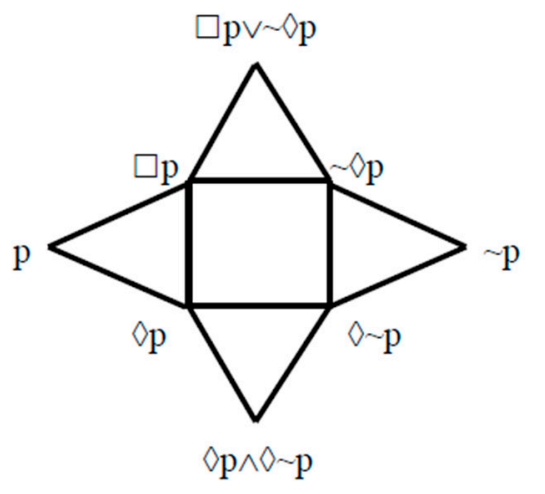

non-contingency ( necessity or impossibility)

necessity impossibility

actuality (outside link)

possibility innecessity

contingency (possibility and innecessity)

Figure 3. System $\Sigma 2$.

This system, often called " $\mathrm{T}$ ", is a basic modal system. Because the operators are interdefinable, it can be expressed in terms of necessity or of possibility,

$\begin{array}{cccc}\square \mathrm{p} & \square \sim \mathrm{p} & \sim \nabla \sim \mathrm{p} & \sim \diamond \mathrm{p} \\ \sim \square \sim \mathrm{p} & \sim \square \mathrm{p} & \diamond \mathrm{p} & \diamond \sim \mathrm{p} .^{2}\end{array}$

\section{Propositional Relations}

The Schoolmen also used a square of opposition to illustrate the relations among propositions connected by "and" $(\wedge)$ and "or" $(\vee)$. The strong operator $S$ here represents conjunction: $p \wedge q(" p$ and $\left.\mathrm{q}^{\prime \prime}\right)$ and the weak operator $\mathrm{W}$ represents (inclusive) disjunction $\mathrm{p} \vee \mathrm{q}($ " $\mathrm{p}$ or $\mathrm{q}$ "). The relations are between the "molecular" propositions $\mathrm{p} \wedge \mathrm{q}$ and $\mathrm{p} \vee \mathrm{q} . \Sigma 2$ is required, since there is an outside link to "atomic" propositions, those not joined by these connectives. The following implications indicate the outside link:

$$
\begin{array}{ll}
{[\mathrm{p} \wedge \mathrm{q}] \supset \mathrm{p} \text { and }[\mathrm{p} \wedge \mathrm{q}] \supset \mathrm{q}} & {[\sim \mathrm{p} \wedge \sim \mathrm{q}] \supset \sim \mathrm{p} \text { and }[\sim \mathrm{p} \wedge \sim \mathrm{q}] \supset \sim \mathrm{q}} \\
\mathrm{p} \supset[\mathrm{p} \vee \mathrm{q}] \text { and } \mathrm{q} \supset[\mathrm{p} \vee \mathrm{q}] & \sim \mathrm{p} \supset[\sim \mathrm{p} \vee \sim \mathrm{q}] \text { and } \sim \mathrm{q} \supset[\sim \mathrm{p} \vee \sim \mathrm{q}]
\end{array}
$$

The propositional octagon (Figure 4):

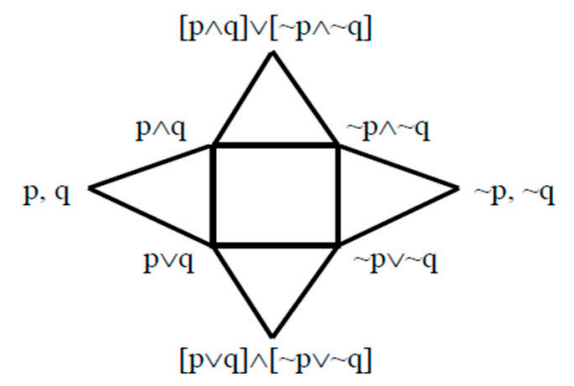

Figure 4. The propositional octagon.

\section{Quantification}

The square of opposition has also been applied to quantified propositions. Here, we may read the logical operators as quantifiers; the strong operator $S$ is the universal quantifier: " $\forall x$ " and the weak operator W is the existential quantifier; " $\exists \mathrm{x}$ ". The letter " $\mathrm{a}$ " stands for a "thing" and the Greek letter phi $(\phi)$ indicates a proposition containing a ( $\phi \mathrm{a}$; say, "Alice is good"); the letter " $x$ " is a variable in the proposition ( $\phi \mathrm{x})$. Again, $\Sigma 2$ is needed, since the rules of quantificational logic,

2 Hughes and Cresswell [1], pp. $30 \mathrm{ff}$. 


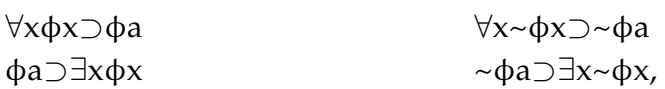

constitute an outside link. Here, connections to and from propositions are not governed by a quantifier ${ }^{3}$.

The octagon of quantification (Figure 5):

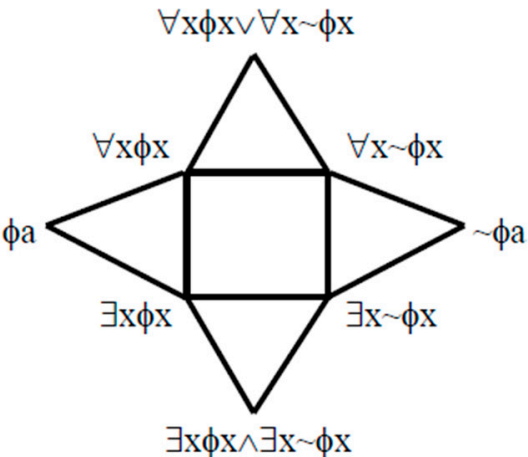

everything is good or everything is not good

universality

Alice is good existence Alice is not good

particularity

something is good and something is not good

Figure 5. The octagon of quantification.

\section{Deontic Logic}

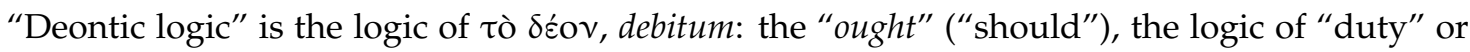
"obligation" ". Ways of signifying moral notions lie deeply embedded in our languages and can be formulated logically in systems compatible with various ethical views. The Schoolmen touched upon the matter, Leibniz formulated a deontic system, and more recent systems date from G. H. Von Wright $[3,4]^{5}$.

For the strong operator $\mathrm{S}$ in deontic logic, I use the letter "O" ("ought") in the proposition "Op", and for the weak operator W, I use the letter " $\mathrm{M}^{\prime}$ ("may") in "Mp". Either symbol can be taken to relate a free moral agent, say, Socrates, to the state-of-affairs that ought to obtain (Op: "Socrates should bring it about that $\mathrm{p}$ "; and $\mathrm{Mp}$ : "Socrates may bring it about that $\mathrm{p}$ ").

$\mathrm{O}$ and $\mathrm{M}$, too, are interdefinable:

$\begin{array}{ll}\mathrm{Op}={ }_{\mathrm{df}} \sim \mathrm{M} \sim \mathrm{p} & \text { Socrates should do } \mathrm{p} \text { just in case he may not leave } \mathrm{p} \text { undone } \\ \mathrm{Mp}={ }_{\mathrm{df}} \sim \mathrm{O} \sim \mathrm{p} & \text { Socrates may do } \mathrm{p} \text { just in case he is not obliged to leave } \mathrm{p} \text { undone }\end{array}$

"O $\sim \mathrm{p}$ " can be abbreviated as "Fp" ("Socrates is forbidden to do $\mathrm{p}$ "). Also, Op can be read "Socrates need not do $\mathrm{p}^{\prime}$, abbreviated " $\mathrm{Np}^{\prime \prime}$. We have, then, these equivalences:

3 Traditionally, the square has been applied to general propositions governed by words like omnis, aliquis, nullus, aliquis...non, $\mathrm{a}$ in the square:

$$
\begin{array}{ll}
\text { all } & \text { none } \\
\text { some } & \text { some...not }
\end{array}
$$

"All horses whinny" is an example of a universal, affirmative proposition. However, if it is read "for anything: if it is a horse, then it whinnies", no inference to "some horse whinnies" can be made unless at least one horse is stated to exist. This so-called "Fregean" analysis has the advantage of separating a statement of relation and a statement of existence.

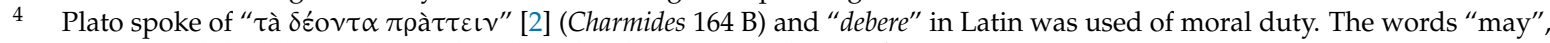
"must", and the like are obviously to be taken here only in the moral sense.

5 See Redmond 1998, 1999b and 2000, 1990 [5-9]; for the Scholastics, see [10], cap. 5; for Leibniz's "modalia juris" in his Elementa juris naturalis [11] see [12], pp. 420ss); see also G. H. Von Wright (1951) [3,4].

6 Note that the phrases "ought not", "should not", and "may not" (in my dialect of English) usually mean $\mathrm{O} \sim \mathrm{p}$ rather than $\sim \mathrm{Op}$ or $\mathrm{M} \sim \mathrm{p}$. 


$$
\begin{aligned}
& \mathrm{Op}=\sim \mathrm{M} \sim \mathrm{p} \\
& \mathrm{O} \sim \mathrm{p}=\sim \mathrm{Mp}=\mathrm{Fp} \\
& \sim \mathrm{Op}=\mathrm{M} \sim \mathrm{p}=\mathrm{Np} \\
& \sim \mathrm{O} \sim \mathrm{p}=\mathrm{Mp},
\end{aligned}
$$

as well as the implications Op $\supset \mathrm{Mp}$ : (if Socrates must, he may) and $\mathrm{Fp} \supset \mathrm{Np}$ (if he is forbidden, he need not).

Scholastic moral theologians, in their "probabilist" discussions, of which we shall speak below, called the disjunction of the contraries "law (lex)", since Socrates must either do p or not do p. They called the conjunction of the subcontraries "freedom (libertas)", since Socrates may, but need not, do p (in other words, $\mathrm{p}$ is "optional", a "work of supererogation"). The hexagon of $\Sigma 1$ displays these relations, since there is no outside link to actual behavior; the fact that $\mathrm{p}$ ought to be the case does not mean that it will be the case (Op $\supset \mathrm{p}$ is obviously invalid, as is $\mathrm{Fp} \supset \sim \mathrm{p})$. Leibniz displayed these relations in a square of opposition, and I include his terms in italics (for him, "optional" was "indifferent"); I also include the Scholastic "law" and "freedom" (Figure 6).
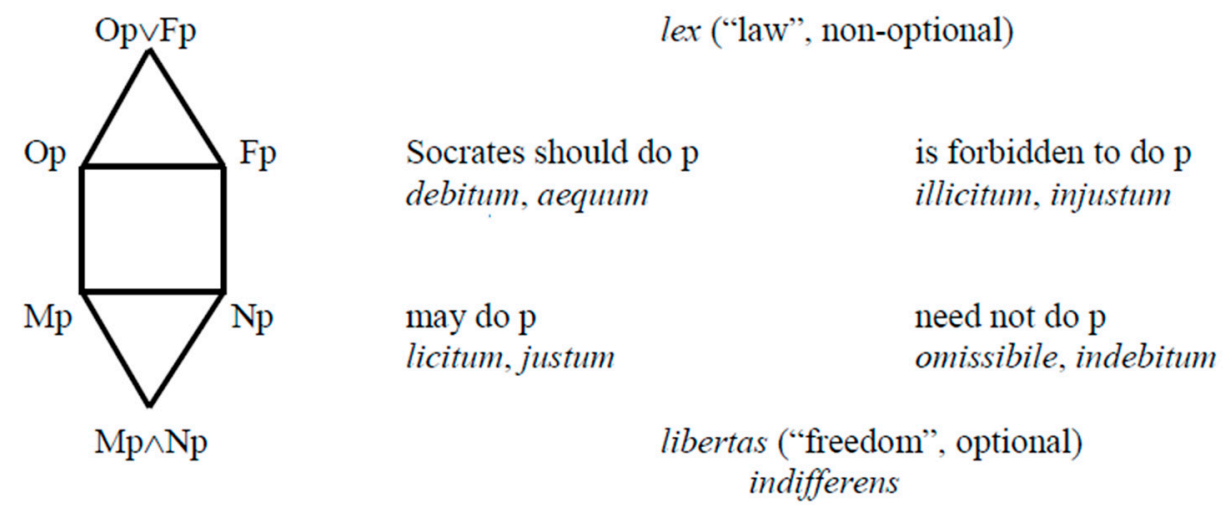

Figure 6. The square of opposition.

Again, we can express this system with a single operator:

$$
\begin{array}{llll}
\mathrm{Op} & \sim \mathrm{Op} & \sim \mathrm{M} \sim \mathrm{p} & \sim \mathrm{Mp} \\
\sim \mathrm{O} \sim \mathrm{p} & \sim \mathrm{Op} & \mathrm{Mp} & \mathrm{M} \sim \mathrm{p} .
\end{array}
$$

Leibniz used his square in a legal context, but the Schoolmen were concerned with individual conscience, the "moral law".

\section{Behavior}

If we introduce a link to actual behavior, we have, as it were, systems of "virtue and vice". Socrates does his duty $(\mathrm{Op} \wedge \mathrm{p}, \mathrm{O} \sim \mathrm{p} \wedge \sim \mathrm{p})$ or fails to do it $(\mathrm{O} \sim \mathrm{p} \wedge \mathrm{p}, \mathrm{Op} \wedge \sim \mathrm{p})^{7}$. The schoolmen spoke of "veritatem manifestare" , and we can use an octagon to express the outside link to "compliance"; that is, the implications

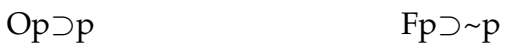

$$
\begin{aligned}
& \mathrm{p} \supset \mathrm{Mp} \quad \sim \mathrm{p} \supset \mathrm{Np} \text {. }
\end{aligned}
$$

The octagon of good behavior (Figure 7):

\footnotetext{
7 Here, we must take "p" as "Socrates does p", so that Op should be read "it ought to be the case that Socrates does p". 8 Merkelbach [13], p. 63.
} 


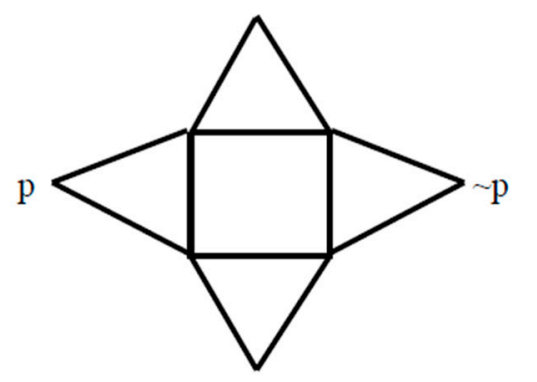

Socrates should

Socrates does

Socrates may
Socrates should not

Socrates does not

Socrates need not

Figure 7. The octagon of good behavior.

For example, Socrates pits the olives when his wife Xanthippe told him to, and he does not eat

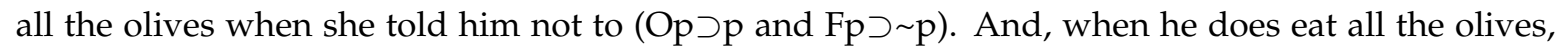
Xanthippe told him he might, and when he doesn't pit any olives, she said he doesn't have to ( $p \supset \mathrm{Mp}$ and $\sim \mathrm{p} \supset \mathrm{M} \sim \mathrm{p})$.

On the other hand, we have an "octagon bad behavior" when $\mathrm{p}$ and $\sim \mathrm{p}$ are switched, and, in the case of lex, compliance would become "non-compliance" (Figure 8):

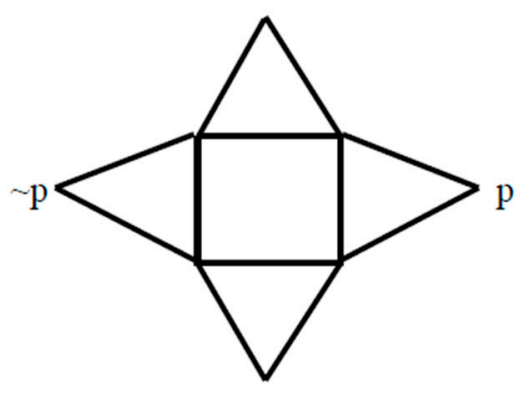

Socrates does not Socrates does

Figure 8. The octagon of bad behavior.

Here Socrates doesn't pit the olives when Xanthippe told him to, and he eats all the olives when

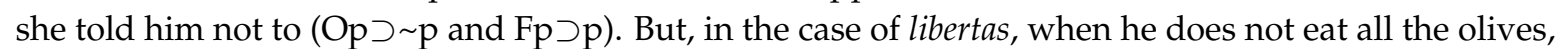
Xanthippe said he might, and when he pits the olives, she told him he didn't have to $(\sim \mathrm{p} \supset \mathrm{Mp}$ and $\mathrm{p} \supset \mathrm{Np})$.

\section{The Logic of Knowledge}

Traditionally, good behavior requires that the person be able to act both knowingly and freely. If Socrates acts freely, he then meets the following condition, where "Dp" stands for "Socrates decides freely to bring about the state-of-affairs $\mathrm{p}$ " and lambda " $\lambda$ " stands for "the physical laws of nature are in force" ${ }^{\prime \prime}$ :

$$
\mathrm{Dp} \wedge \diamond[\lambda \wedge \sim \mathrm{Dp}]
$$

"Socrates decides to bring about $\mathrm{p}$ but it may be that while the laws of nature hold he does not so decide" $"$.

Besides being free, Socrates must also know or at least believe that he has a duty. We may take knowing and believing in the sense of Jaako Hintikka's "logic of the two notions" [14] ${ }^{10}$. In fact, the logics of knowledge and belief correspond to the two logical systems $\Sigma 2$ and $\Sigma 1$.

9 Thus, the state-of-affairs $\mathrm{p}$ is not physically necessary; nor is it therefore logically necessary $(\diamond[\lambda \wedge \sim \mathrm{p}] \supset \sim \square \mathrm{p})$.

10 Hintikka 1962, Section 1.1. "Epistemic" refers to knowing, although it is used in a general sense to include believing; "doxastic" refers only to believing. 
In Hintikka's epistemic logic, the operator " $K$ " relates a knower (say, Socrates) to what he knows, the state-of-affairs $\mathrm{p}$ in "Kp", meaning "Socrates knows that $\mathrm{p}$ "11, This means that Socrates knows that $\mathrm{p}$, where the knowledge is truth-entailing, that is:

${ }^{*} \mathrm{~K} p \supset \mathrm{p}$ and $\mathrm{K} \sim \mathrm{p} \supset \sim \mathrm{p}$

* $\mathrm{p} \supset \sim \mathrm{K} \sim \mathrm{p}$ and $\sim \mathrm{p} \supset \sim \mathrm{Kp}$ what Socrates knows is true he does not know what is false.

We have, then, an outside link to "truth", to what is actually true or false "outside knowledge". In the following octagon, $\mathrm{Kp} \vee \mathrm{K} \sim \mathrm{p}$ means that Socrates knows whether $\mathrm{p}$ is true or false, and $\sim \mathrm{K} \sim \mathrm{p} \wedge \sim \mathrm{Kp}$ that he does not know whether $\mathrm{p}$ is true or false (Figure 9).

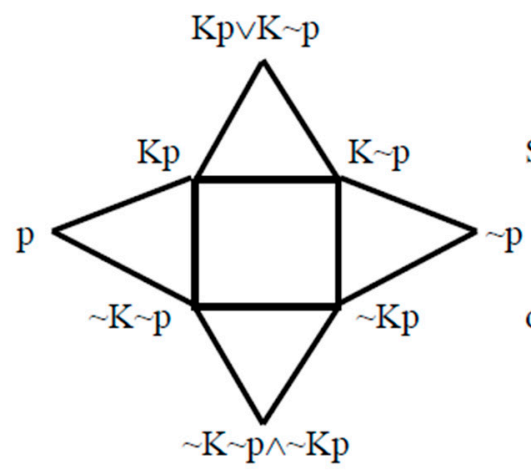

knowledge: Socrates knows whether $\mathrm{p}$

Socrates knows that $\mathrm{p}$

$\mathrm{p}$ is true

does not know that $\sim \mathrm{p}$

ignorance: Socrates does not know whether $\mathrm{p}$

Figure 9. The octagon of knowledge and ignorance.

The octagon with the deontic operator O (Figure 10, in terms of Socrates's duty in regard to p):

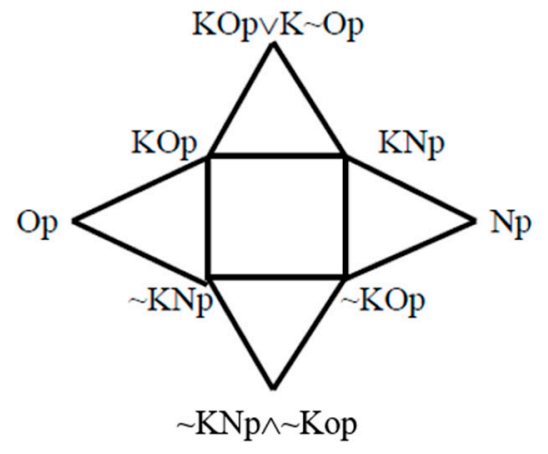

Socrates knows whether he should do $\mathrm{p}$

knows he should

he should

does not know he need not

does not know he should

Figure 10. The octagon with the deontic operator $\mathrm{O}$.

\section{The Logic of Belief}

In Hintikka's doxastic logic, the operator " $\mathrm{B}$ " relates Socrates to his opinion, that is, the state-of-affairs $\mathrm{p}$ in "Bp" ("Socrates believes that $\mathrm{p}$ "). "Belief", in this sense, presupposes basic rationality and does not have the negative connotations that the word may have in a Platonic tradition ( $\delta$ ó $\alpha$, opinio). Nevertheless, belief, although it follows from knowledge (Kp $\supset \mathrm{Bp})$, is not truth-entailing (Bp $\supset \mathrm{p}$ and $\mathrm{Bp} \supset \mathrm{Kp}$ are invalid). Therefore, there is no outside link, and $\Sigma 1$ must be used to display the relation (Figure 11):

11 We need not use Hintikka's symbol "a" for the epistemic agent. He uses the letters " $\mathrm{P}$ " and " $\mathrm{C}$ " to indicate the weak counterparts of $\mathrm{Kp}$ and $\mathrm{Bp}(\sim \mathrm{K} \sim \mathrm{p}$ and $\sim \mathrm{B} \sim \mathrm{p})$, which he glosses as "it is possible, for all (Socrates) knows, that $\mathrm{p}$ " and "it is compatible with everything that (Socrates) believes that $\mathrm{p}^{\prime \prime}$. 


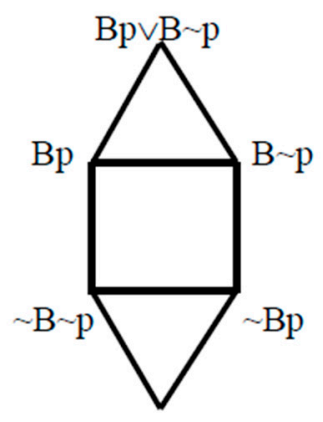

$\sim \mathrm{B} \sim \mathrm{p} \wedge \sim \mathrm{Bp}$

Socrates believes that $\mathrm{p}$ or he believes that not-p

belief

believes that $\mathrm{p}$

unbelief

does not believe that not-p

wavering (doubting)

Socrates neither believes that not-p nor does he believe that $p$ disbelief

believes that not-p

does not believe that $\mathrm{p}$

Figure 11. $\Sigma 1$ with the operator B.

\section{The Logic of Knowledge and Belief Combined}

Since epistemic logic contains the doxastic logic, we may combine the octagon of knowledge with the hexagon of belief. The double lines are implications linking the two systems:

$$
\begin{array}{ll}
\mathrm{Kp} \supset \mathrm{Bp} & \mathrm{K} \sim \mathrm{p} \supset \mathrm{B} \sim \mathrm{p} \\
\sim \mathrm{B} \sim \mathrm{p} \supset \sim \mathrm{K} \sim \mathrm{p} & \sim \mathrm{B} \supset \sim \mathrm{Kp} .
\end{array}
$$

The diagram (Figure 12):

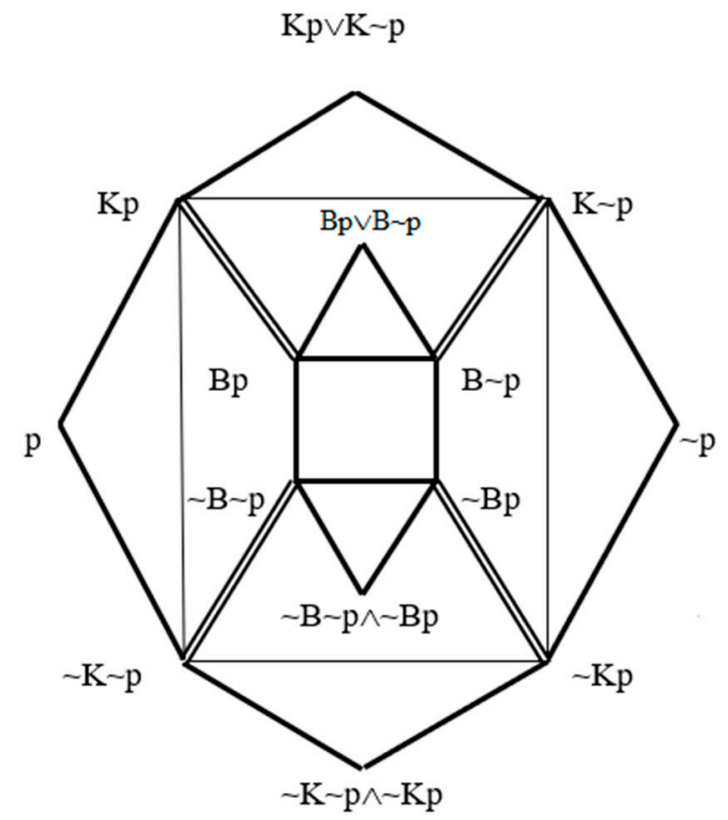

Socrates knows whether $\mathrm{p}$

believes that $\mathrm{p}$ or believes that $\sim \mathrm{p}$

neither believes that $\sim \mathrm{p}$ nor believes that $\mathrm{p}$

does not know whether $\mathrm{p}$

Figure 12. The octagon of knowledge with the hexagon of belief combined.

This network of implications runs from "certitude" to "quandary"12.

\section{Probabilism}

The Schoolmen around the 17th century passionately discussed how we are to judge when the moral agent is bound by law or has the liberty to act as he pleases. The purpose of this metaethical controversy, called "probabilism"13, was to describe the "good conscience", particularly in the face of

12 Also, $[K p \vee K \sim p] \supset[B p \vee B \sim p]$ and $[\sim B \sim p \wedge \sim B p] \supset[\sim K \sim p \wedge \sim K p]$.

13 The word was first used by the Spanish Dominican Bartolomé de Medina (1527-1580). 
moral dilemma. A number of theories or systemata ("systems") developed, and they all relied upon a calculus of thinking about duty - combining, in effect, an epistemic logic with a deontic logic.

Obviously, we may do something when we are sure, that is, when we know ${ }^{14}$ that we may $(\mathrm{KMp} \supset \mathrm{Mp}$; also, KFp $\supset \mathrm{Fp})$ or even if we are unsure but believe that we may $(\mathrm{BMp} \wedge \sim \mathrm{KMp})$. But what do we do if we "waver": neither believing that the act is forbidden nor that it is allowed ( BFp $\wedge \sim \mathrm{BMp})$ ? Or how are we to act when ethicists themselves have sharply different views on what is right?

Participants in the discussion distinguished several "states of mind" according to the degree of rationality of these states. ${ }^{15}$ They took this rationality as a "probability of grounds" of the reasons or arguments brought to defend their positions. "Probable" here does not mean "likelihood" (say, of heads or tails turning up at the toss of a coin); a "probable" argument is rather one that "can be defended by sound arguments (rationes graves), and is quite close to Hintikka's notion of "defensibility"16.

These are the chief states of moral thinking ${ }^{17}$ :

* Certainty: Socrates is sure that he must or may effect the state-of-affairs $\mathrm{p}$ if he has a "sound grounds" for his attitude (KOp, KMp or their negative forms) and no reason, or only "slight

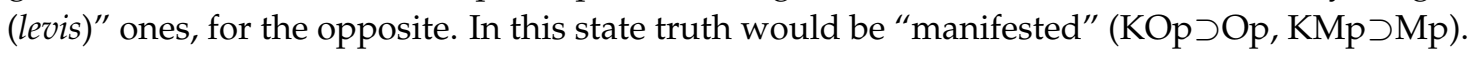
He then knows whether he may or may not act:

$$
\mathrm{KMp} \vee \mathrm{KFp}
$$

* Opinion: Socrates believes that he should or may effect $\mathrm{p}$ when his reasons are "sound enough" or "sounder than the opposite". "And so, although the truth is not "manifested, still there is a notable appearance of the truth"18. Hence, he opines that some act is licit or forbidden:

$\mathrm{BMp} \vee \mathrm{BFp}$

and he is then said to be "afraid of being wrong".

14 On being certain and knowing, see Hintikka Sections 5.8 and 5.9.

15 Merkelbach, 62. The doctrine of St. Thomas Aquinas ([15], 2-2:1-16.) lies in the background. He distinguished among knowing, opining, suspecting, and wavering (scire, opinari, suspicari, dubitare) according to assent to a proposition (assensionem) and adherence (adhaesio) to its truth-value. His "epistemic calculus" can be approximately described with the help of the operators Kp and Bp (Figure 13):

$\begin{array}{llllllll} & \mathbf{p} & & & & \sim \mathbf{p} \\ \text { wavering } & & & \sim \mathrm{B} \sim \mathrm{p} & \sim \mathrm{B} \sim \mathrm{p} \wedge \sim \mathrm{Bp} & & & \\ \text { suspecting } & & \mathrm{Bp} & & & & \mathrm{B} \sim \mathrm{p} & \\ \text { opining } & \mathrm{Kp} & & & & \mathrm{K} \sim \mathrm{p}\end{array}$

Figure 13. St. Thomas Aquinas's "epistemic calculus".

For Thomas faith is truth-entailing but knowledge-eschewing, for when someone assents to $\mathrm{p}$ on religious grounds, then $\mathrm{p}$, but also Kp. Hintikka calls such a state not logically, but "epistemically", inconsistent ( $\mathrm{K}[\mathrm{p} \wedge \sim \mathrm{Kp}]$ is a theorem of the

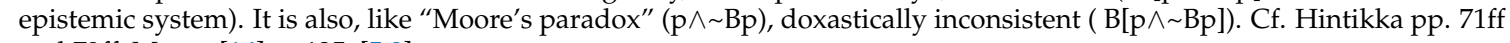
and 79ff, Moore [16] p. 125; [5,9].

16 Hintikka, Section 2.6. Any argument, not only moral, can be "probable". The concept goes back to Aristotle's "dialectical" arguments: $\dot{\varepsilon} \xi \dot{\varepsilon} \nu \delta \delta \dot{\xi} \omega v$ : those that seem true "to all or most or the wise; to all or most of them or to the best known or esteemed", Topica I (100B22) [17].

17 Merkelbach, 62-63. These "systems" (with their variations) are highly nuanced, and our symbolic rendering is only approximate.

18 Merkelbach, 63-4; vide Redmond 1998. There are degrees of the probable: "truly and solidly" (probable), "quite", "more", "much more (or less)", "most probable", "equally probable", ... (ibid. 66-67); a "fuzzy logic" would represent these differences. 
* Wavering ${ }^{19}$ : Socrates wavers "positively" when he suspends assent because the reasons for both positions (Fp and Mp) are "equally sound". Hence in wavering, he does not believe that he may not, nor does he believe that he may:

$\sim \mathrm{B} \sim \mathrm{Mp} \wedge \sim \mathrm{BMp}$.

* Ignorance or "negative wavering": Socrates suspends his assent when his reasons for both sides ("parts") are totally lacking. He therefore does not know whether he may or may not act:

$\sim \mathrm{K} \sim \mathrm{Mp} \wedge \sim \mathrm{KMp}$.

The similarity between the four Scholastic and the "epistemic states" is obvious and can be compared in this diagram, which combines epistemic, doxastic, and deontic logics (Figure 14):

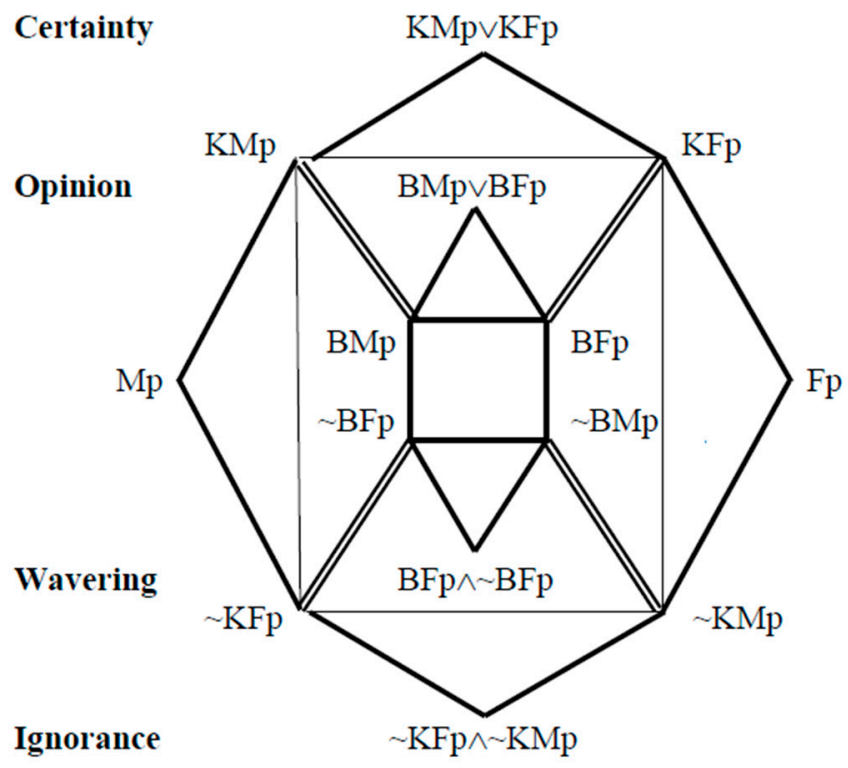

Socrates knows whether he may do $\mathrm{p}$

he believes that he may do $\mathrm{p}$ or he believes that he may not do $\mathrm{p}$ he neither believes that he may not do $\mathrm{p}$ nor does he believe that he may do $\mathrm{p}$

he does not know whether he may do $\mathrm{p}$

Figure 14. Epistemic, doxastic, and deontic logics combined.

The double lines connect knowledge with belief:

* that Socrates knows that he may do $\mathrm{p}$ implies that he believes that he may: KMp $\supset \mathrm{BMp}$ (also KFp $\supset$ Bfp);

* that he does not believe that he may not do implies that he does not know that he may not: $\sim \mathrm{BFp} \supset \sim \mathrm{Kfp}$ (also $\sim \mathrm{Mp} \supset \sim \mathrm{KMp}$ ).

These are the (epistemic) truth-entailing relations:

* that Socrates knows that he may do $\mathrm{p}$ implies that he may: KMp $\supset \mathrm{Mp}$ (or KFp $\supset \mathrm{Fp}$ );

* that he may do $\mathrm{p}$ implies that he does not know that he is forbidden: Mp $\supset \sim \mathrm{KFp}$ (or Fp $\supset \sim \mathrm{KMp}$ ).

The various "systems" lie on a spectrum between the extreme positions called rigorism or tutiorism (a moral act demands certitude) and laxism (any opinion, even a doubtfully sound one, may be followed $)^{20}$. Other systems are mitigated tutiorism (the soundest view is always to be followed), probabiliorism (the sounder view is to be followed), aequiprobabilism (a position at least as sound as its opposite may be followed), and moderate probabilism (a solidly probable viewpoint may be followed).

19 "Suspicion" is included in wavering, for "reason accepts what is little as if it were nothing" (quod parum est quasi nihil accipit ratio), [15] (1-2:14:4); Merkelbach, 63.

20 Both positions were condemned by the Catholic church (Merkelbach, 70 and 72). For a more detailed description see Redmond 1998. The probablist did not lack humor; the Cistercian John Caramuel was called the "Prince of the Laxists", and another laxist, Antonio Diana, a Theatine priest, was said to be "the lamb who taketh away the sins of the world" (agnus qui abstulit peccata mundi)! 


\section{Analogy}

In summary, in an "analogy of proportionality", there are a number of interpretations of the systems $\Sigma 1$ and $\Sigma 2$ according to their strong and weak operators (Figure 15):

strong $\frac{\text { necessary }}{\text { weak }}=\frac{\text { all }}{\text { possible }}=\frac{\text { and }}{\text { ar least one }}=\frac{\text { should }}{\text { may }}=\frac{\text { know that }}{\text { not know that not }}=\frac{\text { believe that }}{\text { not believe that not }}$

Figure 15. Interpretations of the systems $\Sigma 1$ and $\Sigma 2$.

All these "ratios" embody $\Sigma 1$, and $\Sigma 2$ also applies to those having an "outside link": necessary (the link to actuality), all (to existence), and (to atomic propositions), and knowing (to truth). There is also an analogy between the epistemic, doxastic, and deontic logics described and those found in Scholastic probabilism.

Funding: This research received no external funding.

Acknowledgments: I would like to thank the anonymous reviewer who pointed out some additional papers that he thinks it is worth recommending for further reading. One of these papers, namely (5) by Lorenz Demey, is not published yet. Here is the list (in alphabetic order): (1) Béziau, J.-Y. New light on the square of oppositions and its nameless corner, Logical Investigations, 10 (2003), pp. 218-232; (2) Blanché, R.: Quantity, Modality, and Other Kindred Systems of Categories. Mind 61, 369-375 (1952); (3) Blanché, R.: Structures intellectuelles: Essai sur l'organisation systématique des concepts. Vrin, Paris (1966); (4) Blanché, R.: Sur l'opposition des concepts. Theoria 19, pp. 89-130 (1953); (5) Demey, L., Aristotelian diagrams for semantic and syntactic consequence, Synthese (forthcoming), doi:10.1007/s11229-018-01994-w; (6) Demey, L., Using syllogistics to teach metalogic, Metaphilosophy 48, 575-590 (2017); (7) Jacoby, P.: A Triangle of Opposites for Types of Propositions in Aristotelian Logic. The New Scholasticism 24, pp. 32-56 (2012); (8) Miclet, L. and Prade, H., Analogical proportions and square of oppositions, A. Laurent et al (eds.) IPMU 2014, Springer, 2014, pp. 324-334; (9) Sesmat, A.: Logique II. Les Raisonnements. Hermann, Paris (1951).

Conflicts of Interest: The author declares no conflict of interest.

\section{References}

1. Hughes, G.H.; Cresswell, M.J. An Introduction to Modal Logic; Methuen and Co.: London, UK, 1968.

2. Plato. Charmides.

3. Von Wright, G.H. Deontic Logic. Mind 1951, 60, 1-15. [CrossRef]

4. Von Wright, G.H. An Essay in Modal Logic; North Holland: Amsterdam, The Netherlands, 1951.

5. Redmond, W. A Logic of Religious Faith and Development. In The Rationality of Theism; Rodopi: Amsterdam, The Netherlands, 2000; Number 73; pp. 35-59.

6. Redmond, W. Lógica Simbólica para Todos; University of Vera Cruz: Xalapa, Vera Cruz, Mexico, 1999.

7. Redmond, W. Lógica. deber, virtud. Areté Revista de filosofía 1999, 11, 755-772.

8. Redmond, W. Conscience as Moral Judgment: The Probabilist Blending of the Logics of Knowledge and Responsibility. J. Relig. Ethics 1998, 26, 389-405.

9. Redmond, W. A Logic of Faith. Philos. Relig. 1990, 27, 165-180. [CrossRef]

10. Knuuttila, S. Modalities in Medieval Philosophy; Routledge: London, UK, 1993.

11. Leibniz, G.W. Elementa juris naturalis (1671-2). In Sämtliche Schriften und Briefe; O. Reichl: Darmstadt, Germany, 1927; Volume 6, pp. 431-485.

12. Burkhardt, H. Logik und Semiotik in der Philosophie von Leibniz; Philosophia Verlag: Munich, Germany, 1980.

13. Merkelbach, B.H. De virtutibus moralibus. In Summa Theologiae Moralis; Desclée de Brouwer: Louvain, Belgium, 1954; Volume 2.

14. Hintikka, J. Knowledge and Belief: An Introduction to the Logic of the Two Notions; Cornell University Press: Ithaca, NY, USA, 1962.

15. Aquinas, T. Summa Theologiae. 
16. Moore, G.E. Ethics; Holt and Co.: New York, NY, USA, 1912.

17. Aristoteles. Topics.

(c)

(C) 2019 by the author. Licensee MDPI, Basel, Switzerland. This article is an open access article distributed under the terms and conditions of the Creative Commons Attribution (CC BY) license (http:/ / creativecommons.org/licenses/by/4.0/). 